\title{
Dimensiones de la justicia en el mundo contemporáneo (Cuatro estudios de derecho comparado)
}

\section{Ángel Samuel Carreón Ibarra*}

Mauro Cappelletti (1927 - 2004) Doctor en Derecho por la Universidad de Florencia y profesor de Derecho en esa misma institución, así como en la Stanford Law School y presidente de la Facultad de Derecho en el Instituto Universitario Europeo con sede en Florencia. Desde su primera obra en 1955, sobre la jurisdicción constitucional de la libertad, hasta las obras colectivas, que tuvieron alcance mundial, relativas al acceso a la justicia, se observa que, si bien no son muy extensas y más bien de corte ensayístico, son sólidas, profundas y originales.

Esta obra tiene su origen en cuatro seminarios impartidos durante los cursos de invierno de la Facultad de Derecho de la Universidad Autónoma de México, celebrados la última semana de noviembre de 1990, las aportaciones de Mauro Cappelletti fueron recopiladas para la creación de esta obra, dichos seminarios se titulan; "El derecho comparado: Método y finalidades (Una propuesta metodológica)", "La justicia constitucional y supranacional", "La justicia social: Acceso a la justicia y la responsabilidad del jurista en nuestra época" y "Acceso a la justicia de los consumidores".

Primer seminario. El derecho comparado: Método y finalidades (una propuesta metodológica). En este seminario se aborda el aumento de la difusión e importancia de los estudios y las enseñanzas de tipo comparativo. Según Cappelletti, hay cuatro razones importantes de este fenómeno.

1.- El aumento de los intercambios económicos, personales y culturales entre las naciones, lo que incrementa las relaciones jurídicas a nivel transnacional.

2.- La naturaleza transnacional de fenómenos como la contaminación, los

*Egresado de la Licenciatura en Derecho de la Universidad de Guadalajara abogamer117@gmail.com 
asentamientos urbanos incluso las comunicaciones vía satélite.

3.- La tendencia de ciertos valores, particularmente en el campo de los derechos humanos, citando como ejemplo las Convenciones Europea y Americana de Derechos Humanos.

4.- La tendencia a crear organizaciones políticas y económicas multinacionales, como la Comunidad Económica Europea.

Se mencionan seis "fases" o "etapas" metodológicas dentro de cuyo cuadro se debe desarrollar la investigación comparativa. La primera etapa, menciona que no es necesario que exista una semejanza del material jurídico objeto de comparación, lo que sí se requiere, en cambio, es un punto de partida común prejurídico, un problema o una necesidad social real que comparten dos o más países o sociedades a las cuales se quiere aplicar el análisis comparativo.

La segunda etapa, es el análisis comparativo, se trata de encontrar las normas, instituciones y procesos jurídicos con los que los países examinados han intentado resolver el problema que comparten. Se resalta, como tales intervenciones jurídicas, normativas, institucionales, o procesales, pueden ser muy diversas de país a país, sin que esto prive de significado a la comparación.

La tercera etapa. Es la investigación de las razones que puedan explicar las analogías, pero sobre todo, las diferencias en las soluciones adoptadas en respuesta a un mismo problema: razones históricas, sociológicas, éticas.

La cuarta etapa. Consiste en las tendencias evolutivas que pueden ser convergentes o divergentes.

La quinta etapa. Es la valoración de las soluciones adoptadas en cuanto a su eficacia o ineficacia en la resolución del problema del cual ha arrancado la investigación.

La sexta etapa. Se trata de prever desarrollos futuros, porque, sobre la base de la investigación realizada, puede sacar a la luz tendencias evolutivas, las cuales presumiblemente están destinadas a continuar y a difundirse, al estar radicadas en problemas y necesidades reales de la sociedad, y al haber sido valoradas a la luz de los datos empíricos concernientes a su eficacia en la solución del problema.

En su segundo seminario. La justicia constitucional y supranacional. Se habla de la necesidad de poner un límite y control al poder político, a fin de prevenir la inevitable corrupción que, tarde o temprano, deriva de un uso incontrolado, y por 
tanto arbitrario del poder. La importancia que han tomado los derechos humanos y la nueva conciencia del hecho de que ciertos derechos no deben ser violados, porque su violación no ofende únicamente a la víctima, sino a toda la sociedad y, en última instancia, a toda la humanidad. Se aborta también, la necesidad de crear instrumentos eficaces para la protección de los derechos, que sean de naturaleza jurisdiccional, confiados a órganos suficientemente independientes respecto del poder político, al cual tienen como misión controlar. Esto no significa negar la importancia de la justicia administrativa que, no obstante, representa usualmente un control de legalidad, esto es, de conformidad del acto administrativo con la ley, no con la constitución. Se presentan posibles soluciones a dicho problema y entre ellas, la solución jurisdiccional. Finalizando con el análisis comparativo de las diferentes razones de las diferencias entre las "soluciones" adoptadas por los diversos países y también las grandes "tendencias evolutivas".

El tercer seminario. La justicia social: acceso a la justicia y la responsabilidad del jurista en nuestra época. En este seminario se critica el dogmatismo jurídico que ha conducido el positivismo, lo que ha terminado por reducir al derecho a su aspecto normativo, olvidando los otros elementos, no menos esenciales: sujetos, instituciones, y procedimientos. Como resultado de este dogmatismo tenemos una simplificación de las tareas y responsabilidades del jurista, juez, abogado y estudioso, tareas que, según dicha posición, deberían limitarse a un mero conocimiento y a la mera aplicación aséptica, pasiva y mecánica de las normas en la vida práctica, en la enseñanza y en el análisis científico. En esta postura formalista la interpretación de la norma no es otra cosa que el resultado de un cálculo conceptual de estructura deductiva, fundado en una idea del ordenamiento como sistema de normas cerrado, completo y jerarquizado, con la doctrina del "silogismo judicial, para el cual la decisión es también el resultado objetivo de un cálculo deductivo".

Se aborda el tema de la pobreza económica como un primer obstáculo para acceder a la justicia, ya que, los menos pudientes, recurren a la asistencia del defensor técnico, esto es, el abogado, ya sea en calidad de asesor legal o de defensor en juicio. Esta es la solución típica del Estado pre-social, para sostener el "deber honorífico" de la abogacía de prestar gratuitamente sus servicios a los no pudientes. Se trata de una solución con la cual el Estado, al tiempo que 
aparenta ocuparse del problema se desinteresa de hecho él, porque establece una obligación genérica de la profesión, dejando a ésta la tarea de cumplirla. Esto ocasiona que los abogados rehúyan a su cumplimiento o lo hagan de mala voluntad y de manera inadecuada, la mayoría de las veces.

En el cuarto seminario. El acceso a la justicia de los consumidores. En este se ofrece una perspectiva sobre el mercado libre, que ha demostrado ser un instrumento esencial para el incremento de la propiedad general. Se presenta la postura que una sabia política de protección al consumidor, lejos de ser un instrumento de distorsión del mercado, es hoy, un instrumento indispensable para garantizar la libertad efectiva del mercado, al igual que la política dirigida a asegurar la libre competencia. Presentando una paradoja de esta temática, esto es, el hecho que precisamente para asegurar la libertad del mercado, se hacen necesarias las intervenciones normativas, administrativas y judiciales equilibradoras, ya sea sobre el plano de la protección de los consumidores, como en el de la política en materia de competencia. Por otra parte, toda intervención asume dificultades particulares en el cuadro del carácter cada vez más vasto y multinacional de la economía contemporánea, por lo que nuevamente se pone particular atención en la conveniencia de no crear diversidades artificiosas e innecesarias, tales que constituyan obstáculos al comercio internacional, obstáculos que terminarían por dañar, en último análisis a los propios consumidores.

Para finalizar se agrega una última observación, en relación con el acceso a la justicia. El gran movimiento mundial para el acceso a la justicia, hasta ahora incompleto en gran medida, ha llevado, en la esfera jurídica, a una nueva perspectiva, la que se ha llamado "perspectiva de los consumidores". La vieja concepción veía el derecho sólo en la perspectiva de los productores y de sus productos: el legislador y la ley, el juez y la resolución judicial, la administración pública y el acto administrativo. La perspectiva del acceso a la justicia consiste en cambio en dar preeminencia a la perspectiva del consumidor del derecho y de la justicia: el individuo, los grupos, la sociedad, con sus necesidades, reclamos, aspiraciones, y por tanto también con sus obstáculos (jurídicos, pero también económicos, políticos, culturales, psicológicos, etcétera). 


\section{Bibliografía}

Dimensiones de la justicia en el mundo contemporáneo

(Cuatro estudios de derecho comparado)

Traducción de Héctor Fix Fierro.

Editorial Porrúa, S.A. México 1993

ISBN: 968-452-653-9 
